\title{
Indicadores Chave de Desempenho Logístico Aplicado à Cadeia de Suprimentos Verde: Um Estudo de Caso
}

\author{
Ismael Setuval Gomes ${ }^{1}$; Alyne Leite de Oliveira ${ }^{2}$; Hudson Josino Viana ${ }^{3}$; \\ Antonio Raniel Silva Lima ${ }^{4}$; Maria Patrícia de Alencar ${ }^{5}$
}

\begin{abstract}
Resumo: Este artigo busca verificar como os indicadores chave de desempenho podem contribuir para a melhoria dos processos na cadeia de suprimentos verde de uma empresa de Crato no Ceará, culminando para o alinhamento dos processos de transformação com a estratégia empresarial. Sua importância se justifica por proporcionar e enriquecer o entendimento da cadeia de suprimentos verde através de uma abordagem sustentável e a possibilidade de implementação das práticas ambientais abordadas, afirmando ainda a importância das técnicas administrativas no meio social, econômico e ambiental. O método utilizado para o alcance do objetivo proposto se estruturou a partir de um estudo de caso, com abordagem qualitativa, cujos instrumentos de coleta foram entrevista semi estruturada com o gestor responsável e observação assistemática não participante dos processos vigentes no lócus da pesquisa, para que fosse feita a análise à luz da literatura vigente, estruturada a partir de artigos, monografias e livros que abordam a temática em estudo. Pôde-se evidenciar a cadeia de suprimentos verde, os parâmetros de avaliação de cada etapa e sua importância para os objetivos da empresa, destacando assim que a empresa não criou para si indicadores de desempenho, mas que ela se utiliza de métodos de processos impostos pelas certificadoras como indicadores para transformar seus processos a fim de alinharem estes a estratégia da empresarial adotada.
\end{abstract}

Palavras Chave: Logística. Indicadores de desempenho. Sustentabilidade.

\section{Key Performance Indicators Applied to Logistics Green Supply Chain: A Case Study}

\begin{abstract}
This article has the aim to verify how key performance indicators can contribute to the improvement of the processes in the green supply chain of Crato company in Ceará, culminating in the alignment of transformation processes with business strategy. Its importance is justified by providing and enriching the understanding of the green supply chain through a sustainable approach and the possibility of implementing the environmental practices addressed, also affirming administrative techniques in the social, economic and environmental environment. The method used to reach the proposed objective was structured from a case study with the qualitative approach, whose collection instruments were semi-structured interview with the manager responsible and unsystematic nonparticipant observation of the current processes at the focus of the research, for to be analyzed in light of the current literature, structured from articles, monographs and books that address the theme under study. The green supply chain, the evaluation parameters of each stage and its importance to the company's objectives can be evidenced, thus highlighting that the company did not create performance indicators for itself, but that it uses process methods imposed by the company. certifiers as indicators to transform their processes in order to align these with company strategies adopted.
\end{abstract}

Keywords: Logistics. Key Performance Indicators. Sustainability.

${ }^{1}$ Graduado em Administração pelo Centro Universitário Doutor Leão Sampaio/UNILEÃO-ismaelgomes12@outlook.com ${ }^{2}$ Especialista em Logística Empresarial, Orientadora da Graduação e Pós-Graduação da Faculdade Vale do Salgado/FVS e do Centro Universitário Doutor Leão Sampaio/UNILEÃO, membro do Comitê de Ética em Pesquisa alyneleite@leaosampaio.edu.br

${ }^{3}$ Especialista em controladoria e auditoria, professor de Marketing da Faculdade Vale do Salgado/FVS e coordenador do curso técnico em Administração da Escola Profissional Francisca de Albuquerque Moura/EPFAM-hudson.josino@gmail.com ${ }^{4}$ Professor da Graduação e Pós-Graduação da Faculdade Vale do Salgado/FVS e do Centro Universitário Doutor Leão Sampaio/UNILEÃO, Mestrando em Administração de Empresas (UNIFOR) - raniel@ leaosampaio.edu.br ${ }^{5}$ Graduada em Administração pelo Centro Universitário Doutor Leão Sampaio/UNILEÃO-patriciaalencar133@gmail.com

244 Id on Line Rev. Mult. Psic. V.12, N. 41, p. 244-265, 2018 - ISSN 1981-1179

244 Edição eletrônica em http://idonline.emnuvens.com.br/id 


\section{Introdução}

Barbieri (2016) afirma que os recursos naturais são classificados como materiais extraídos do meio ambiente e que podem ser utilizados e transformados em produtos para o uso cotidiano e a melhoria de vida do ser humano. Por outro lado, Dias (2017) destaca que desde a revolução industrial o meio ambiente vem sofrendo uma exploração crescente dos recursos naturais, não apenas para a expansão urbana da sociedade, como por exemplo a construção de pavimentações, prédios, áreas de lazer e o desmatamento para a criação das próprias cidades, mas também com a extração destes recursos para a produção de bens, afim de suprir as necessidades de consumo da também crescente população.

Este meio frenético de produzir reflete sobre a cadeia de suprimentos um volume de materiais gigantescos e em igual proporção, os resíduos sólidos derivados de todo o processo de transformação em produtos acabados, provocando assim uma crescente preocupação com relação aos processos de transformação destes materiais no que tange à necessidade por sustentabilidade junto com a preservação dos recursos naturais inerentes as empresas responsáveis pelos processos.

Ainda segundo Dias (2017) os processos de industrialização causam várias adversidades, entretanto as mais percebidas pelos consumidores e a população em geral são os locais de depósito dos dejetos provenientes dos processos produtivos, que degradam o ecossistema e deixam cada vez mais fragilizada a saúde e o bem-estar dos seres humanos.

Os processos logísticos de cunho sustentável que envolvem os ambientes, tanto macro como micro, buscam pela melhor qualidade dos métodos de industrialização ou transformação de materiais, buscando o equilíbrio voltado para a preservação dos recursos naturais agregando valor no tocante a sustentabilidade empresarial e social.

Segundo Paladini e Bridi (2013) para atender aos valores das estratégias empresarias compreendidos a toda a organização, e atender as necessidades dos clientes, as empresas podem buscar pela implementação dos Indicadores Chave de Desempenho aplicando-os nos seus processos para que haja melhoria nos mesmos e o acompanhamento das métricas empresariais adotadas.

Frente a esse contexto busca-se com este estudo verificar como os indicadores chave de desempenho podem contribuir para a melhoria dos processos na cadeia de suprimentos verde de uma empresa da cidade de Crato no Ceará, culminando para o alinhamento dos processos de 
transformação com a estratégia empresarial. Para o alcance de tal objetivo, se fez relevante discutir sobre os aspectos inerentes à sustentabilidade, adentrando o conceito de cadeia de suprimentos, bem como identificando como as práticas de sustentabilidade agregam valor à mesma.

Para se chegar aos objetivos traçados, esta pesquisa utilizou como base de estudos uma bibliografia que conta com artigos e livros que abordam os assuntos relacionados ao tema e foi realizado um estudo de caso, onde foram observados os processos de coleta, armazenagem e distribuição física, bem como as práticas de sustentáveis que envolvem as etapas da cadeia de suprimentos, atrelados a uma entrevista semi estruturada com o gestor da empresa produtora e exportadora de mel da cidade de Crato-Ce.

Esta pesquisa justifica-se pelo entendimento sobre a cadeia de suprimentos verde, e análise dos indicadores chave de desempenho sobre a mesma para um melhor alinhamento com a estratégia empresarial, através de uma abordagem sustentável, viabilizando assim o conhecimento e a possibilidade de implementação destas práticas por parte dos gestores que buscam um desempenho mais amplo nos processos gerenciais voltados para a produção sustentável.

Desta forma este estudo agrega valor e afirma a importância acadêmica e prática dos conhecimentos técnicos que são desenvolvidos e estudados pela ciência administrativa, demonstrando a sua assertividade, eficiência e contribuição diante do meio não só mercantil, mas que também demonstrando a sua influência para o meio social e ambiental em que se encontram inseridos.

\section{Novo Parâmetro Produtivo: Sustentabilidade}

Segundo Dias (2017) ao longo das décadas de 60 e 70 as organizações não governamentais de todo o mundo e sem apoio algum, apenas com uma carga de responsabilidade e determinação, obtiveram êxito ao demonstrar para grande parte do público consumidor e não consumidor e aos gestores mundiais, que a extração, e a degradação dos recursos naturais causadas através de agentes poluidores, poderiam acabar extinguindo as matérias primas naturais necessárias para a produção de todo o planeta em pouco tempo, já que o manejo adequado dos recursos que deveriam existir nas empresas não eram vigentes. 
Dias (2017) destaca que a partir da conferência Rio 92 surgiram novas propostas de gerenciamento visando as melhores práticas de produzir dentro do parâmetro sustentável a fim de se adequarem às novas tendências exigidas pelo mercado.

Segundo Barbieri (2016), foi elaborada a definição de desenvolvimento sustentável pela Comissão Mundial para o Meio Ambiente e Desenvolvimento, afirmando que o desenvolvimento sustentável estaria restrito a produtividade de bens e serviços para que fossem supridas as conveniências da geração, mas atentando para que não comprometesse o futuro das próximas no que se diz respeito a extração de recursos naturais para a produção.

Xavier e Corrêa (2013) aborda que os consumidores não estão satisfeitos apenas com os índices de redução dos impactos ambientais causados pelo consumo e pós-consumo dos produtos e as práticas que as indústrias ou varejo adotam para minimizar os mesmos, essas informações e métodos devem sim estar presentes nos produtos e vivas e enraizadas nas empresas, entretanto o consumidor e o grande público priorizam as informações em relação aos processos de produção e as práticas que possam erradicar os impactos de produção sobre o meio ambiente e a sociedade.

Barbieri (2016) afirma essa linha de tendência quando diz que o meio social está atento aos meios produção sustentável, e cita que há um grande volume de leis aprovadas ao longo dos anos voltadas para a responsabilidade ambiental das empresas, devido ao esclarecimento prestado pelas organizações não governamentais, que estão em constante desenvolvimento de pesquisas ambientais para despertar a crítica da realidade ambiental do país por parte das pessoas comuns que devem entender a necessidade de produzir sem extinguir ou degradar os recursos naturais.

Segundo Jabbour e Jabbour (2013) pode-se adotar práticas de gerenciamento ambiental focados nos projetos de produtos que durante o seu uso ou pós uso não causem danos ao meio ambiente, embalagens que sejam reutilizáveis, produtos que não sejam tóxicos na sua montagem e avaliação da sua vida útil, o gerenciamento abrange ainda o foco da produção envolvendo controle de resíduos advindos da transformação em produto acabado, modo de extração, embalagem e consumo.

Assim, para que as empresas possam sobreviver com o novo comportamento de seus consumidores, estas precisam adaptar-se ao novo contexto produtivo, tomando como base os conceitos e entendimentos relacionados a estratégia das organizações em relação a seus clientes e mercados como um todo. 


\section{Estratégia Empresarial}

Segundo Cruz (2017), para que as empresas possam enxergar cenários prospectivos e executar suas atividades com o intuito de sobressair-se nestas perspectivas, deve-se desenvolver na organização o planejamento estratégico, que se trata do caminho a ser percorrido pela empresa e que tem sua base fundamentada na missão, visão e valores que por sua vez sofrem influências externas no seu desenvolvimento, entre algumas influencias estão os governos, clientes, tecnologias, clima entre outros.

Oliveira (2014) relata que a estratégia empresarial é a conduta elaborada para que possa ser executada e seguida pelos gestores das empresas afim de obterem de forma assertiva e diversificada, as metas pré-estabelecidas e que estas lhes tragam retorno sobre os seus investimentos.

Essa administração requer um conjunto de análises e ideias que visam posicionar os empreendimentos de uma forma em que estes venham a comunicar-se com o mercado em que estão inseridos, onde as empresas ofertem o que é necessário, levando-as a vantagens competitivas e preparando-as para as cargas de oscilações positivas e negativas geradas por estes (GONÇALVES e FILHO, 2006).

Para Mintzberg, et al. (2007) a estratégia empresarial trata-se da criação de uma cadeia que fornece valores e que funciona a partir de uma infinidade de processos diversificados, estas atividades por sua vez são elaboradas com base no melhor posicionamento da empresa em relação ao mercado, entretanto este posicionamento não será estático, cabendo a empresa diversifica-lo sempre ao modo de estar à frente de seus concorrentes.

Desse modo, compreende-se que a estratégia empresarial tem como finalidade promover a interação entre mercado e empresas, em que as organizações absorvam todo o movimento do ambiente mercadológico, desta forma as empresas não seguem às escuras em seu funcionamento, mas com um norte dado pela estratégia e preparadas para adaptar-se as novas transformações econômicas e sociais por meio da leitura deste movimento (OLIVEIRA, 2014).

Com as novas tendências de consumo pautadas na sustentabilidade de processos de transformação das matérias primas em produtos acabados, as empresas buscam saciar estas carências dos consumidores, criando e adequando as suas estratégias produtivas a estes parâmetros, cabendo a cada uma averiguar sua cadeia de suprimentos logística e alinhando-as 
as necessidades de produtos e processos do mercado, assim poderão manter-se ativas, mas para que se possa explanar de maneira adequada a cadeia de suprimentos faz-se necessário a compreensão da logística em si e a partir deste contexto abordar a cadeia de suprimentos verde

\section{Compreendendo a Logística}

Segundo Ferreira (1986 apud CORONADO, 2013) a definição da palavra logística deriva dos vocábulos Grego e Francês, que faziam referência a parte de cálculos, a matemática de uma forma geral, com operações voltadas para o cotidiano utilizadas por pessoas comuns e das estratégias de guerras respectivamente, em que havia toda uma elaboração e alocação de tropas em relação ao número de soldados, munições para o combate e sua duração, alimentos paras os soldados, medicamentos e o posicionamento nos territórios inimigos, com o passar das décadas este vocábulo ou palavra foi evoluindo até chegar ao significado atual.

Pozo (2010) define que a logística delimita-se a parte estratégica da cadeia que envolvem as funções de locomoção, compreendidos na aquisição de materiais, seus processos de transformação e distribuição para o consumidor buscando o aperfeiçoamento destas atividades, entretanto com um enfoque na redução dos valores destes processos, Ballou (1997 apud CORONADO, 2013) mencionam ainda a logística atrelada ao meio empresarial, afirmando que trata-se da operação responsável pelo transporte, armazenamento e estocagem, a partir da compra de materiais até chegar a sua destinação final que seria consequentemente o cliente, não restringindo-se apenas a produtos físicos, mas também a uma contínua rede de dados que facilitem a locomoção destes produtos afim de que os mesmos estejam nas mãos dos consumidores em tempo hábil, agregando valor a estes produtos,

Ao se observar essa evolução no termo, percebe-se que o cenário exige não apenas a adequação deste, mas também e principalmente o atendimento às exigências na conjuntura vigente. A ABRALOG (2017 apud DIAS, 2017) e Wanke, Figueiredo e Fleury citam que a logística é integrante da cadeia de abastecimento que está incumbida do comando adequado, para delinear e executar a fluência das matérias e suas respectivas informações, a partir da extração ou compra de matérias primas até a destinação final, que seria o fornecimento ao consumidor buscando associação de valores para cativar os clientes como um todo. Esse 
contexto traz consigo a necessidade do tratamento estratégico atrelado à integração dos componentes operacionais, bem como a integração da cadeia.

O Counsil of Supply Chain Management Professional (2011 apud XAVIER e CORRÊA, 2013) enfatiza o papel do gestor no tocante ao processo em questão, visto que o mesmo requer atividades de planejamento, implementação e controle das vias entre as aquisições, transportes, armazenagens de estoques, ponto de ressuprimento, pedidos de clientes, canal de comunicação de informações até a chegada ao consumidor final. Onde, esta parte da logística lida direta e inversamente com todos os processos envolvidos, para que se gere valores e a satisfaça dos clientes.

Confirmando assim, o que menciona Ludovico (2010) quando destaca que a logística são processos estrategicamente elaborados a partir de uma procura por um determinado produto, que buscam o controle efetivo do escoamento das matérias primas, produtos acabados ou em processo de transformação e de seus respectivos dados, priorizando a execução destes ao modo de conseguir a maior redução possível dos custos logísticos deste escoamento, assim a logística diz respeito diretamente a embalagens, unitização, manuseio, armazenamento, demanda, transportes e equipamentos. Surge assim a possibilidade de controle através do uso de métricas ou indicadores de desempenho, viabilizando todo o processo.

Visto que a logística busca menores custos aos produtos finais e ainda manter o fluxo de materiais ou produtos a fim de atender a demanda exigida pelo mercado, agregando mais um valor que seria disponibilização das mercadorias em tempo considerado satisfatório aos consumidores e nos locais em que são solicitados, alocando-se na cadeia de suprimentos.

\section{Cadeia de Suprimentos Verde}

Tendo em vista que a logística, segundo Novaes (2015), é responsável por gerenciar todo o processo produtivo de bens e serviços, do ponto de entrada de matérias primas a sua transformação em produtos acabados e o seu destino final, ou seja, o consumidor, visando agregar valor de tempo, lugar, informação e qualidade satisfazendo assim os interesses dos seus clientes; a cadeia de abastecimento é um sistema elaborado com determinados métodos especificamente necessários para a disponibilização das matérias primas (BERTAGLIA, 2016), então surge a necessidade de transporta-las e transforma-las em materiais manufaturados, junto 
a estas etapas do processo buscando implementar uma percepção tangível ou não tangível satisfatória para o consumidor que esteja compreendido entre o lugar desejado e o tempo desejado.

Na cadeia de suprimentos verde, segundo Emmett e Sood (2010 apud LOPES et al. 2013), acontece o mesmo processo do Supply Chain Management (gerenciamento da cadeia de suprimentos-SCM), mas com um fator a mais que se estende por toda a cadeia, que seria a necessidades de se atentar para a sustentabilidade em cada etapa da cadeia produtiva, ou seja, a partir da compra, do transporte deste material, da armazenagem, da sua transformação em produto acabado, do seu transporte ao ponto de distribuição e o seu consumo e pós consumo, em todos estes processos devem haver um atuação forte do gerenciamento ambiental das empresas que buscam o melhor gerenciamento da cadeia de suprimentos verde.

Já os autores Fan Wang e Gupa (2011 apud XAVIER e CORRÊA, 2013) trazem a cadeia de suprimentos verde como uma idéia para alavancar a atuação mais abrangente da logística reversa dentro do gerenciamento da cadeia de suprimentos, deste modo ela não atuaria apenas no pós consumo mas também na minimização da extração das matérias primas naturais e substituindo com maior frequência pelo uso de materiais e energias renováveis, trazendo ao tema central que seria criar uma cadeia de valores arraigados aos processos sustentáveis até o destino final do produto.

Xavier e Corrêa (2013) destacam que a cadeia de suprimentos verde ou logística ambiental está atrelada ao gerenciamento e práticas ambientais, adotados pelas empresas e indústrias direcionadas ao SCM a fim de reduzirem os impactos ambientais do processo de aquisição, extração, transporte, armazenagem, o uso eficiente de energias para a produção e os resíduos sólidos descartados durante a transformação da matéria prima em produto acabado até o seu destino final.

Partindo assim da necessidade de gerenciamento dos processos logísticos verdes com a finalidade de conseguir vantagem competitiva, as empresas elaboram métodos ou indicadores para que haja a padronização e a qualidade destes processos e consequentemente dos produtos acabados, estes indicadores são elaborados ou estabelecidos de acordo com o mercado em que a empresa atua e na sua estratégia empresarial. 


\section{Indicadores Chave de Desempenho}

Para que esses processos ocorram de forma assertiva a atender ao requisito sustentabilidade, logísticos e estratégicos, as empresas podem e devem aplicar os indicadores chave de desempenho que, segundo Takashina e Flores (1996 apud OHASHI e MELHADO, 2004) trata-se de uma ferramenta da gestão da qualidade que verifica os níveis de desempenho criados pelas organizações que contribuam para o crescimento das empresas, estes indicadores são intrínsecos a cada organização, pois é preciso levar em consideração as estratégias e os objetivos adotados a serem alcançados por cada uma delas.

Gonçalves (2013) destaca que os indicadores de desempenho são métodos extremamente importantes para a gerencia da cadeia de suprimentos como um todo, pois permitem o acompanhamento dos melhores processos e identificam, através das avaliações, as melhorias de determinados pontos considerados mais frágeis da cadeia, permitindo a intervenção dos gestores afim de que estes possam elevar e alinhar o ponto fraco com os parâmetros exigidos pela estratégia da empresa.

Segundo Albertin e Albertin (2016) os fatores que culminam para a melhoria ou avanço das empresas no que tange ao desempenho estratégico, estão ligados ao contexto em que empresas se encontram, ou seja, as estagnações e mudanças mercadológicas fora da organização e fatores intrínsecos a elas também contribuem para tal fim. A partir deste alinhamento de estratégia junto aos pontos que devem ser acompanhados surgem inúmeros fatores chave que devem ser afunilados para que haja concentração nos principais pontos a serem acompanhados, mensurados e melhorados.

Xavier e Corrêa (2013) comentam que existem alguns parâmetros que são utilizados como base para mensurar as métricas logísticas estabelecidas a partir da estratégia empresarial, como por exemplo recursos logísticos, nível de utilização destes recursos, custos de logística, níveis de emissões de resíduos sólidos provenientes dos processos da cadeia, níveis de serviços que agregam valor como por exemplo: tempo, lugar, modificações entre outros. Estes parâmetros variam de empresa para empresa, pois suscitará exclusivamente da estratégia adotada e os objetivos a serem atingidos,

Segundo disposto na NBR ISO 14031 estão apresentados alguns do principais indicadores de desempenho ambiental gerencial relacionados a política ambiental, número de iniciativas implementadas para a prevenção da poluição, número de níveis gerenciais com 
responsabilidade ambientais específicas, número de funcionário que têm requisitos ambientais em sua descrição de trabalho, número de fornecedores e prestadores de serviço consultados sobre questões ambientais, número de prestadores de serviço contratados com SGA implementado ou certificado, níveis de conhecimento obtidos pelos participantes de treinamento, entre outros.

Desta forma os indicadores fazem o fechamento do elo entre estratégia empresarial, logística e a sustentabilidade ambiental desenvolvida pelas empresas, buscando a mensuração das práticas ambientais logísticas alinhando-as a estratégia da empresa para que se consigam os objetivos, em relação a vantagens competitivas e na agregação de valor pelo processo de produção voltado para a sustentabilidade.

\section{Procedimentos metodológicos da Pesquisa}

A metodologia abordada para se chegar aos objetivos estabelecidos foi de caráter descritiva, pois assim como destaca Gil (2010, p.28) "são pesquisas descritivas aquelas que visam descobrir a existência de associações entre variáveis", assim tornou-se relevante o uso deste método para viabilizar as relações entre os assuntos abordados nesta pesquisa, colaborando para um entendimento do estudo além de evidenciar os pontos de convergência.

Utilizou-se ainda de fontes bibliográficas, que segundo Marconi e Lakatos (2017, p.200) esse tipo de pesquisa "abrange toda a bibliografia já tornada pública em relação ao tema de estudo, desde publicações avulsas, boletins, jornais, revistas, livros, pesquisas, monografias, teses, artigos científicos impressos ou eletrônicos, material cartográfico e até meios de comunicação oral", este tipo de pesquisa proporciona ao pesquisador uma gama completa de materiais ligados ao tema do estudo, para a construção de um melhor embasamento teórico.

A revisão bibliográfica foi estabelecida através de artigos e monografias disponíveis na base de dados do Google acadêmico, utilizando como critério de inclusão palavras chave: KPI, Logística, Cadeia de suprimentos, desenvolvimento sustentável e logística verde; Livros que abordam o assunto pesquisado, documentos elaborados e fornecidos pela empresa.

A pesquisa contou também com fonte documental, que ainda segundo Gil (2010, p.30) "a pesquisa documental vale-se de toda sorte de documentos, elaborados com finalidades diversas, tais como assentamento, autorização, comunicação etc.” Estes documentos foram de 
grande valia para demonstração de resultados e crescimentos obtidos pela empresa, que fazem referência aos temas abordados no referencial teórico, deste modo evidenciando a sua veracidade.

E estudo de caso que, segundo Matias-Pereira (2016), trata-se de uma pesquisa intensa que permite um conhecimento global e de uma grande riqueza de detalhes, possibilitando observar de perto as características da empresa, conhecer seus setores e processos com maior destreza o que não seria viável em outros métodos.

A empresa do estudo em questão está localizada no Nordeste brasileiro, região mais apropriada para a produção de mel orgânico, a empresa tem como princípios a sustentabilidade nos processos e a valorização de apicultores da Agricultura Familiar, que, em momento algum se utilizam de agrotóxicos na colheita do mel. Com mais de 20 anos de experiência na exportação de mel de abelhas para vários países da Europa e América Latina, especializada em comercializar produtos essencialmente orgânicos a empresa prioriza a produção da Região Nordeste tendo em vista o seu potencial. A região, por ser livre de agricultura intensiva, conserva as suas florações sem a utilização de fertilizantes, inseticidas, herbicidas ou fungicidas, portanto livre de agrotóxicos. Dessa forma, a abelha africanizada, que habita o Nordeste Brasileiro em alta escala, é bastante resistente a doenças, anulando completamente a utilização de antibióticos por parte dos apicultores e nunca produzindo mel de floração transgênica (DADOS DA PESQUISA, 2017).

O instrumento para a coleta se deu por meio de entrevista com o gestor da empresa, pois este detêm o conhecimento detalhados dos processos de transformação que serão necessários à pesquisa, ou seja, a cadeia de suprimentos verde, indicadores de desempenho elaborados pelos mesmos e os princípios básicos de estratégia para atender as necessidades dos clientes, assim pode-se obter as informações globais da empresa que corroboram com a pesquisa bibliográfica abordada e atendendo aos objetivos primários e secundários.

Após a coleta dos dados mediante observação e entrevista com o gestor responsável pelo processo, estes dados foram analisados por meio do método da análise de conteúdo (AC). A análise de conteúdo é referida por Minayo, Deslandes e Gomes (2010), como sendo uma exposição de resultados qualitativos, partindo dos depoimentos, sob a forma de discursos sínteses.

O estudo em questão seguiu respeitando os critérios éticos da resolução 510/16 que dispõe sobre as normas aplicáveis a pesquisas em Ciências Humanas e Sociais cujos 
procedimentos metodológicos envolvam a utilização de dados diretamente obtidos com os participantes ou de informações identificáveis ou que possam acarretar riscos maiores do que os existentes na vida cotidiana, na forma definida na Resolução (BRASIL, 2016).

\section{Análise e Discussão dos Resultados}

Com as pesquisas realizadas no site da empresa, entrevista aplicada ao gestor e a observação dos processos, foram obtidos dados e informações de estrutura, cadeia de suprimentos e as atividades fins desempenhadas pela empresa.

A empresa consultada para o estudo de caso está situada na cidade de Crato, região do cariri, interior do estado do Ceará, é uma empresa remanescente de um antigo grupo de exportação que teve suas origens na argentina, foi fundada e implementada no Brasil em 2012, entretanto detém mais de 20 anos de experiência na exportação de mel de abelhas que veio por herança através de seu antigo grupo. Foi iniciada com o intuito de maximizar tanto a produção como a exportação de mel orgânico no nordeste do Brasil, que é o local mais propício para este tipo de cultivo.

No Brasil há uma rica diversificação da caatinga, bioma exclusivamente brasileiro e que tem existência predominante no nordeste do país, tem floração bastante diversificada e de qualidade na produção de um mel diferenciado, com grande aceitação no mercado internacional, esta região também é livre de agricultura intensiva (tipo de agricultura que produz intensivamente grandes quantidades de um único tipo de hortícola ou fruta), conserva suas floras sem a utilização de fertilizantes, inseticidas, herbicidas ou fungicidas, portanto livre de agrotóxicos, a empresa ainda tem como princípio a valorização de apicultores da Agricultura Familiar, que, em momento algum se utiliza de agrotóxicos na colheita do mel garantindo a qualidade do produto.

A empresa recebe o mel de vários estados do nordeste brasileiro, esta coleta de mel é proveniente de épocas de floradas, ou seja, a época em que as plantas desabrocham suas flores e estão prontas para a coleta do néctar, assim as abelhas coletam este néctar para a produção de mel e respectivamente o pólen fertilizando as demais plantas e garantido a perpetuação das espécies nativas. 
A empresa exporta o mel orgânico para vários países da Europa como por exemplo, Dinamarca, França, Inglaterra, Espanha entre outros e também para os Estados Unidos. Para que se possa exportar um produto com um alto padrão de qualidade exigido por europeus e americanos, o gestor destaca que "a empresa investiu e continua a investir em tecnologia e em treinamento, para manter o padrão de qualidade na produção e no aprimoramento da colheita de mel nos apiários de todo o nordeste brasileiro, incentivando cada vez mais os apicultores passando tecnologia e ensinamentos para melhorar o cultivo".

Sem deixar de lado também, a preocupação em contribuir com o social e ambiental, já que para o cultivo do mel orgânico, assim como exposto pelo gestor "uma das exigências é que não haja dentro de uma área compreendida de 7 quilômetros de diâmetro, rios contaminados, trânsito frequente de veículos, queimadas, plantações de sementes transgênicas de qualquer espécie, ou seja, um ambiente preservado sem a ação de degradação humana”. Verifica-se que a empresa busca esse nível de produção sustentável e qualidade através das normas desenvolvidas pelas certificadoras do IBD como por exemplo USDA Organic, Orgânico do Brasil, IBD EcoSocial, entre outras, priorizando desta forma a preservação dos ambientes de exploração para cultivo e propiciando o aumento destas áreas, consequentemente o volume de produção, comercialização do produto e desenvolvimento regional socioeconômico sincronizando com a abordagem de Barbieri (2016).

Figura 1: Certificações

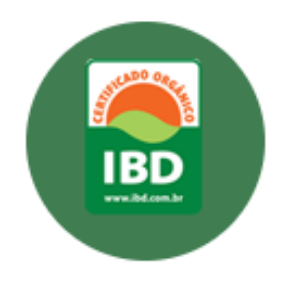

IBD ORGÂNICO

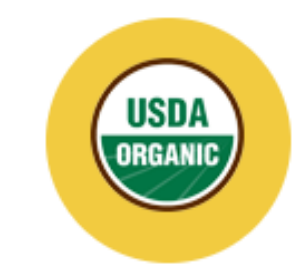

USDA ORGANIC

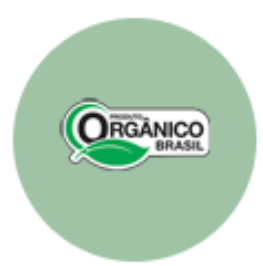

ORGÂNICO BRASIL

Fonte: Dados da Pesquisa (2017).

"Tudo começa com estas áreas de manejo onde possa ser implementada a apicultura orgânica, estes locais devem estar preservados em um entorno de sete quilômetros de diâmetro, 
mas para que haja a comprovação oficial de que a área está apta a atividade produtora de mel orgânico e que a empresa possa efetivar a coleta deste produto, é realizado periodicamente auditorias pelo IBD, o órgão responsável por certificar a qualidade e as conformidades de extração e produção”. Segundo o site do IBD (1991) a auditoria consiste na observação das atividades de extração, transporte, homogeneização, embalagem e armazenagem; análise dos registros e documentos dos processos; averiguação dos equipamentos utilizados e áreas de instalação; rastreabilidade da cadeia; coleta de amostras; identificação e investigação de áreas de risco e entre outras especificações.

A empresa possui suas próprias casas de mel fixas onde é feito a centrifugação e envasamento para envio a central de tratamento, próximas as áreas certificadas de manejo e cultivo do mel, elas estão localizadas no estado do Ceará e Piauí, contando ainda com as unidades móveis de extração que são apiários itinerantes funcionando de acordo com a época do ano de cada região, entretanto a empresa trabalha ainda com a contribuição de apicultores associados ou cooperados.

"Dentro do IBD estão englobadas especificamente as certificações de conformidade para produção e regulamentação de toda a cadeia orgânica para estas associações de apicultores que fica a caráter da Orgânico Brasil, entre alguns dos parâmetros de avaliação estão, os conhecimentos técnicos do sistema de produção orgânica, residir na localidade da atividade produtora, conhecimento e utilização das normas da agricultura orgânica e a área de manejo preservada, a partir deste ponto as colmeias são instaladas e os apicultores, associações de apicultores ou cooperativas cadastradas na base de dados da empresa e com as devidas certificações, fazem o manejo dos apiários duas vezes por semana, estas áreas podem fornecer duas ou até três floradas por ano, após o período da coleta do mel em conformidade com cada região a frota da empresa chega até as unidades para o recolhimento do mel orgânico".

A partir deste ponto e ao longo de vários processos da cadeia, pode-se verificar a relevância e a aplicação da sustentabilidade nos processos de aquisição e transformação das matérias primas, essas atividades desenvolvidas pela empresa são provenientes dos sistemas de gestão ambiental, fato este destacado por Dias (2017) e pelos autores Jabbour e Jabbour (2013). Assim, com a extração pautada na preservação destes meios, torna-se viável o desenvolvimento econômico e social em equilíbrio com o meio ambiente proporcionando a utilização do mesmo 
pelas próximas gerações, além de beneficiar a qualidade de vida da sociedade, aspecto este, abordado por Barbieri (2016) e sem deixar de atender as necessidades estratégicas empresariais.

Este processo ainda traz os aspectos do gerenciamento da cadeia de suprimentos verde como ressaltam os autores Emmett e Sood (2010 apud LOPES et al., 2013) também como Xavier e Corrêa (2017), princípios estes percebidos na fala do gestor quando cita que " $A$ empresa se encontra no nicho de mercado de orgânicos, um nicho que já detém uma preocupação ambiental e também sustentável e de preocupação de onde está saindo aquele produto e se é um ambiente de exploração e sua forma de produção”.

Figura 2: Cadeia de Suprimentos da Empresa

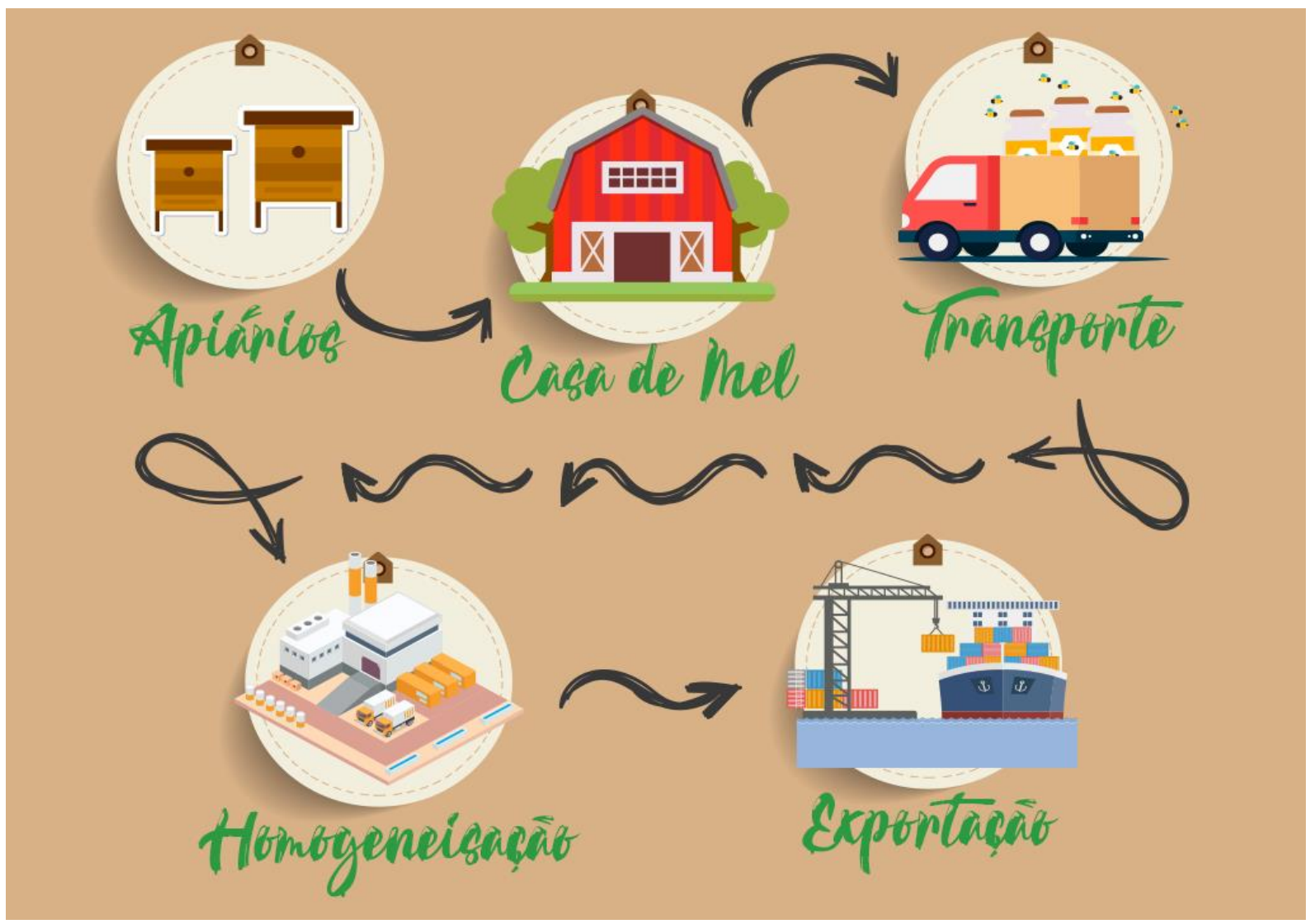

Fonte: Elaborada pelo autor (2017)

Este mel que foi coletado agora será preparado para transporte até a unidade de tratamento. O produto deve passar por três certificações técnicas que asseguram em que estado 
o produto foi enviado, selado com especificações técnicas da localidade e as condições de embalagem e transporte, estas etapas contribuem para a rastreabilidade do produto na cadeia.

“Esta armazenagem para transporte é feita em barris com revestimento de epóxi fenol, uma substância que inibe o contato direto do produto com o metal do barril evitando contaminações, em seguida a estes processos que também fazem parte das exigências do IBD, o transporte é feito até o local de tratamento do produto”. Nestas novas etapas evidenciam-se uma parte do gerenciamento da cadeia de suprimentos, onde há um controle rigoroso do fluxo de informações e materiais que serão conduzidos a transformação em produto acabado, em que existem processos de certificações e cartas de controle determinantes da localidade, qualidade de extração e também como de transporte buscando vincular valor ao produto, aspecto esse demonstrado pelos autores Bertaglia (2016), Xavier e Corrêa (2013) e Pozo (2010).

Figura 3: Selo IBD EcoSocial

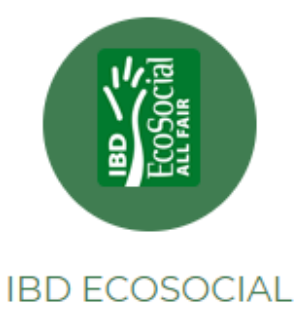

Fonte: Dados da Pesquisa (2017)

Com a chegada do mel in natura em tonéis na sede onde o produto é preparado e embalado para o envio, existe ainda o acompanhado periódico com as auditorias executadas também pelo IBD e pelo Ministério da Agricultura, esta última com uma sala própria e permanente dentro da sede. A empresa conta ainda com a certificação EcoSocial All Fair que faz parte do IBD, que segundo o site do IBD (1991) este atestado é acreditado a empresas que visam desencadear um processo interno de desenvolvimento humano, social e ambiental fomentado por relações comerciais baseadas nos princípios do Comércio Justo com os apicultores envolvidos que participam de iniciativas promovidas pela empresa. São levados em consideração todos os aspectos sociais e ambientais que sejam de natureza negativa para a atividade, deste modo são elaborados planos e ações que contribuam para as melhorias social e 
ambiental do processo aspecto este abordado como indicador pelos autores Xavier e Corrêa (2013).

Assim com os barris de mel na sede da empresa o gestor descreve que estes "são conferidos com os rótulos das casas de mel (associações ou cooperativas) da qual foram enviadas e aferidos com as documentações técnicas, e são direcionados para a coleta de amostras de dados que são enviadas para o setor de controle de qualidade da empresa, para que se façam os testes de acidez, composição química, grau de fluidez, aroma e sabor, desta forma pode-se predeterminar para onde este mel poderá ser enviado de acordo com as preferências de aroma e sabores de cada cliente".

Após a retirada das amostras, o mel ainda nos barris é inserido em um tipo de peneira em inox onde serão separados dos restos de cera provenientes das capas das colmeias, terminado a filtragem do produto, ele é direcionado a uma zona semi limpa, onde existe um bloqueio sanitário em que os funcionário utilizam toucas, botas, luvas e macacões e que antes da entrada passam por uma solução de água e cloro para desinfecção das botas, além disso o local é arejado, limpo e livre de incidência direta de raios de sol tornando-se livre de pragas, neste local o mel em tonéis é empilhado e armazenados aguardando a próxima etapa.

O gestor aborda ainda que "pelo fato do mel ser um produto praticamente pronto para o consumo humano, ele é apenas homogeneizado, ou seja, não sofrendo a ação de aditivos químicos para a sua transformação em produto acabado, ele é apenas misturado com todos os outros tonéis de uma mesma localidade em um silo pelo período de 24 horas", desta forma não são depositados no meio ambiente dejetos ou materiais poluentes provenientes do processo, o que assegura a produção limpa.

Nestas etapas do processo ocorre a transformação da matéria prima de fato em produto acabado, evidenciando-se sustentabilidade do mesmo e sua veia orgânica sanando as preocupações dos consumidores com relação aos processos desta transformação assim como exposto pela autora Xavier e Corrêa (2013), também presente na declaração do gestor “os consumidores se preocupam em saber se o produto que eles estão adquirindo pode ser consumido de uma forma sustentável a partir de suas origens no processo e que não traga nenhum mal ao próprio consumidor, trazendo ainda incremento ambiental para a cidade $e$ para a própria empresa”.

Após este período, o mel é envasado em novos tonéis e confinados em uma sala refrigerada a dezoito graus centrígrados, preservando-os para que não sofram nenhum tipo de 
alteração e aguardando para o envio ao porto do Pécem em Fortaleza no Ceará, onde existe uma unidade de armazenamento refrigerada também a dezoito graus centrígrados e com capacidade de estoque para 1.000 toneladas de produtos prontos para o envio a Europa e Estados Unidos.

Figura 4: Certificadoras
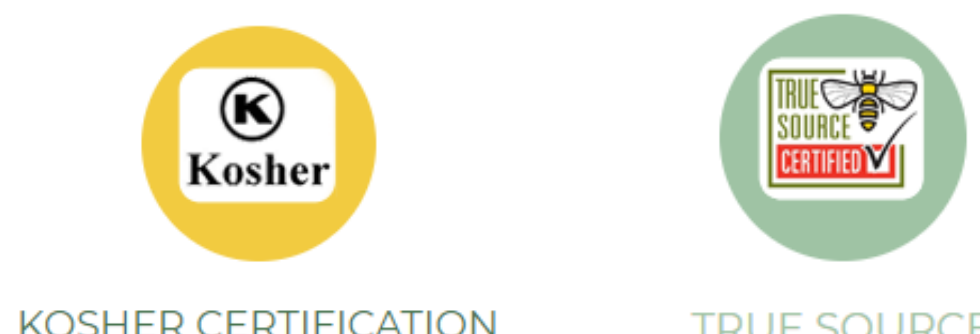

KOSHER CERTIFICATION

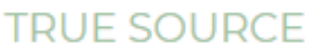

Fonte: Dados da Pesquisa (2017)

A empresa ainda conta com outras duas certificadoras, a Khoser uma delas, segundo o site do IBD (1991) certifica que a empresa produz alimentos pautadas de acordo com as leis judaicas ortodoxas, o que é tido como referência de qualidade em todo o mundo por toda a exigência que se é requerida na produção, extração dos produtos e todos os processos em que são submetidos, ainda há o selo True Source que se trata de empresas que rastreiam todos os passos do produto ao longo da cadeia e certifica a sustentabilidade da mesma, estes dois são reconhecidos internacionalmente.

Afim de que todas estas exigências sejam atendidas para a exportação e a produção orgânica do mel, percebe-se que a empresa utiliza estas métricas estabelecidas pelas certificadoras para tratarem todas as áreas que necessitem de intervenção, buscando as melhorias na cadeia de suprimentos, culminando em resultados satisfatórios para a estratégia da empresa que aborda justamente a exportação do produto orgânico e de alta qualidade sem nenhum tipo de industrialização no processo culminando com o exposto por Paladini e Bridi (2013), direcionando para uma cadeia orgânica sem a degradação do meio ambiente mas, sim contribuindo para a preservação do mesmo ponto este destacado por Barbieri (2016) 


\section{Considerações Finais}

A partir da construção do referencial teórico e análise de discussão dos resultados, podese averiguar que a empresa em questão não se utiliza de indicadores chave de desempenho como descritos pelos autores, ou seja, criados pela própria empresa afim de mensurar suas práticas e processos com o objetivo de verificar a sua conformidade com as estratégias da empresa, entretanto a mesma se utiliza das métricas ou referências estabelecidas pelas certificadoras como parâmetro para verificar se suas práticas e processos estão em conformidade com os objetivos estabelecidos, que no caso da empresa se trata de produzir e exportar o mel orgânico com alta qualidade respeitando a sustentabilidade ao longo de todo o processo.

Como por exemplo a certificação do IBD, exige a preservação ambiental das áreas em torno do cultivo do mel orgânico, esta métrica traz a margem para o gerenciamento do indicador do número de iniciativas implementadas para a prevenção da poluição, indicador este abordado na normatização da ABNT NBR ISO 14003, ou ainda a certificação do Orgânico do Brasil que conta como uma de suas exigências conhecer e implementar os conceitos da agricultura orgânica e o sistema de produção também orgânico, possibilitando o acompanhamento do indicador de número de funcionários com requisitos ambientais em sua descrição de trabalho. Contando ainda com a Certificação EcoSocial que é responsável pelo desenvolvimento econômico e social gerado a partir da produção orgânica, permitindo que os níveis de conhecimento sobre as questões ambientais sejam acompanhados, e a certificação True Source, que se trata do rastreamento do produto por de todas as etapas da cadeia garantido a sua sustentabilidade de produção principalmente na transformação em produto acabado respectivamente permitindo a verificação através dela do indicador de quantidade de resíduos sólidos liberado pelas etapas do processo.

Percebe-se assim ao longo de toda a cadeia a atuação conjunta de todas as certificadoras abordadas, que determinam pautados na produção sustentável (ambiental, social e econômico), as adequações dos processos de extração, área de extração, transporte, transformação em produto acabado e armazenagem, ou seja, determinam os melhores métodos da produção orgânica do mel afim de atender as exigências dos clientes quanto a sua apreensão, a esta 
produção limpa ou orgânica, viabilizando o alinhamento produtivo com a estratégia da empresa culminando nos resultados esperados.

Tendo em vista a relevância deste estudo, sugere-se como pesquisas posteriores a análise dos custos relativos à implementação de práticas sustentáveis na cadeia, bem como o impacto das práticas na vida dos membros.

\section{Referências}

ASSOCIAÇÃO BRASILEIRA DE NORMAS TÉCNICAS. NBR 14031. Gestão ambiental: Avaliação de desempenho ambiental-diretrizes.2015.

Disponível em: $<\mathrm{http}: / / \mathrm{www}$.abnt.org.br/pesquisas/?searchword $=14031 \& \mathrm{x}=0 \& \mathrm{y}=0>$. Acesso em: 20 set. 2017.

ALBERTIN, Alberto Luiz; ALBERTIN, Rosa Maria de Moura. Tecnologia Informação e desempenho empresarial: as dimensões de seu uso e sua relação com os benefícios de negócio. 3. Ed. São Paulo: Atlas, 2016.

BARBIERE, José Carlos. Gestão ambiental empresarial: conceitos, modelos e instrumentos. 4. Ed. Atual e aplicada. São Paulo: Saraiva, 2016.

BERTAGLIA, Paulo Roberto. Logística e gerenciamento da cadeia de abastecimento. 3 . Ed. São Paulo: Saraiva, 2016.

CORONADO, Osmar. Logística integrada: modelo de gestão. 1. Ed. São Paulo: Atlas, 2013.

CRUZ, Tadeu; Manual de planejamento estratégico: ferramentas para desenvolver, executar e aplicar. São Paulo: Atlas, 2017.

DIAS, Marco Aurélio. Introdução à logística: fundamentos, práticas e integração. São Paulo: Atlas, 2017.

DIAS, Rinaldo. Gestão Ambiental: Responsabilidade Social e Sustentabilidade. 3. Ed. Atlas, 2017.

GIL, Antonio Carlos. Como elaborar projetos de pesquisa. 5. Ed. São Paulo: Atlas, 2010.

GONÇALVES, Carlos Alberto; GONÇALVES FILHO, Cid; REIS, Mário Teixeira. Estratégia Empresarial. 1. Ed. São Paulo: Saraiva, 2006.

GONÇALVES, Paulo Sérgio, Logística e cadeia de suprimentos: o essencial. 1. Ed. Barueri: Manole, 2013. 
JABBOUR, Ana Beatriz Lopes Sousa; JABBOUR, Charbel Chiappetta. Gestão ambiental nas organizações: fundamentos e tendências. São Paulo: Atlas, 03/2013.

LAKATOS, Eva Maria; MARCONI, Mariana de Andrade. Fundamentos de metodologia científica. 8. Ed. São Paulo: Atlas, 2017.

LOPES, Lineia Jollembeck; SACOMANO NETO, Mário; SILVA, Eliciane Maria da; LOPES, Francisco Claudio Da Conceição. Influência das Práticas do Green Supply Chain Management no Desempenho Ambiental das empresas do Setor Automotivo Brasileiro. 2013. Disponível em: http://www.anpad.org.br/admin/pdf/2013_EnANPAD_GOL1579.pdf.>. Acesso em: 12.03.2017.

LUDOVICO, Nelson. Como preparar uma empresa para o comércio exterior. São Paulo: Saraiva, 2009.

MATIAS-PEREIRA, José. Manual de metodologia da pesquisa científica. 4. Ed. São Paulo: Atlas, 2016.

MINAYO, Maria Cecilia de Souza; DESLANDES, Suely Ferreira; GOMES, Romeu. Pesquisa Social: teoria, método e criatividade. 29. Ed. Petrópolis: Vozes, 2010.

MINTZBERG, Henry; QUINN, James Brian; LAMPEL, Joseph; GHOSHAL, Sumantra. O Processo da Estratégia: Conceitos, Contextos e Casos Selecionados. 4. Ed. Porto Alegre: Artmed, 2007.

NOVAES, Antônio Gonçalves. Logística e gerenciamento da cadeia de distribuição: estratégia, operação e avaliação. 4. Ed. Rio de Janeiro: Elsevier, 2015.

OHASHI, Eduardo Augusto Maués; MELHADO, Silvio Burrattino. A importância dos indicadores de desempenho nas empresas construtoras e incorporadoras com certificação ISO 9001: 2000. 2004. Disponível em: <ftp://ip20017719.eng.ufjf.br/Public/AnaisEventosCientificos/ENTAC_2004/trabalhos/PAP0 102d.pdf.>. Acesso em: 14 mar. 2017.

OLIVEIRA, Djalma de Pinho Rebouças. Estratégia Empresarial \& Vantagem Competitiva: Como Estabelecer, Implementar e Avaliar. 9. Ed. São Paulo: Atlas, 2014.

PALADINI, Edson Pacheco; BRIDI, Eduardo. Gestão e avaliação da qualidade em serviços para organizações competitivas: estratégias básicas e o cliente misterioso. São Paulo: Atlas, 2013.

POZO, HAMILTON. Logística e Gerenciamento da Cadeia de Suprimentos: Um Enfoque para os Cursos Superiores de Tecnologia. São Paulo: Atlas, 2015. 
WANKE, Peter; FIGUEREDO, Kleber Fossati; FLEURY, Paulo Fernando. Logística e gerenciamento da cadeia de suprimentos: planejamento do fluxo de produtos e dos recursos. 1.Ed. São Paulo: Atlas, 2003.

XAVIER, Lúcia Helena; CORRÊA, Henrique Luiz. Sistemas de logística reversa: criando cadeias de suprimento. São Paulo: Atlas, 2013.

Como citar este artigo (Formato ABNT):

GOMES, Ismael Setuval; OLIVEIRA, Alyne Leite de; VIANA, Hudson Josino; LIMA, Antonio Raniel Silva; ALENCAR, Maria Patrícia de. Indicadores Chave de Desempenho Logístico Aplicado à Cadeia de Suprimentos Verde: Um Estudo de Caso. Id on Line Rev.Mult. Psic., 2018, vol.12, n.41, p.244-265. ISSN: 1981-1179.

Recebido: 14/06/2018

Aceito 25/06/2018 